\title{
Environmental Strategies for Design of Sustainable Buildings in Technique of Green Eco-Architecture
}

\author{
Boris Bielek and Milan Bielek \\ Faculty of Civil Engineering, Slovak University of Technology, Bratislava 813 68, Slovak Republic
}

\begin{abstract}
Architecture is defined as a symbiosis of function, aesthetics, technology and economics. This paper introduces the concept of development of technology in architecture for a sustainable society. The concept is based on a systemic link building-climate-energy. The scientific analysis of this link allows us to define three technical levels of modern architecture. The lowest level is represented by low energy architecture that gives priority to the element of energy. Climate is defined only by physical parameters here. It is characterized by the production of emissions that deplete the Biocapacity of the Earth. Higher level of architecture is represented by green architecture which gives equal priority to both energy and ecology. Climate is defined by physical and chemical parameters here. It is characterized by the tendency of reduction of emissions production and move towards environmentally clean energy, material and water sources. Sustainable architecture represents the target program of development of human settlements in the interaction of society-energy-ecology. It is characterized by the balance of categories nature-man-technology and by minimizing the emissions production to the extent of their coverage by the Earth's ecosystems. This paper introduces design strategy for green building. The basic structure of the strategy defines, and internal structure of the strategy emphasizes, principles and concepts of green buildings. In this strategy, the vital role is played by renewable energy sources as a production technology of the capital provided to man by nature.
\end{abstract}

Key words: Low energy architecture, green architecture, sustainable architecture, green building.

\section{Introduction}

Replacing the age of mechanical manufacturing with the age of informatics has also its undeniable reflection in architecture. It requires interdisciplinary and integrated conceptions. Contemporary information age significantly influences especially technological aspect of the architecture in the most significant fields which is ecology, energy, water and material.

The architecture in its complex is understood as a symbiosis of function, aesthetics, technology and economy (Fig. 1). There is no superiority or inferiority of the mentioned fields of the symbiosis in the architecture. The paper belongs to the field of technology in the architecture. It represents the interaction of mass-ecology-energy emanating from

Corresponding author: Boris Bielek, $\mathrm{PhD}$, associate professor, research fields: physics of buildings, energy efficiency of buildings, aerodynamics and hydrodynamics of buildings, solar building thermal technology and facade technology of buildings. E-mail: boris.bielek@stuba.sk. the natural balance of mass and energy. This common interaction in the specific issue of architecture transforms itself into the system relation building-climate-energy (Fig. 2). In this system relation building represents the mass, thus the material basis and equally constructional design of its details, elements and systems. Climate represents the interior and exterior environment in the complex of its physical and chemical parameters. In the term climate there is also the ecological quality of the environment included. Because the exterior climate has the character of non-stationary problem, the whole system relation has the character of climate dependant process. Energy as a feature of the mass and the quantitative rate of motion, expressing the ability of material systems to produce work on the basis of inner changes is defined in this system relation in the form of quantitative need for providing the required comfort in the interior of the building, situated in particular non-stationary exterior climate. 


\section{Low Energy-Solar Architecture versus Green Architecture}

If in system relation building-climate-energy (in Fig. 1) a clear priority is given to the ecology-climate, then this leads to green architecture (Fig. 2) with primary ecological function, a product of which is comfortable high-performance building with systematic energy saving and healthy interior climate, based on the basis of ecologically clean materials, i.e., green building (Fig. 2). If the subject of our further analyses is green building and the goal is to achieve its above mentioned features, then the method for the way of realization of this intent has the following conception:

The technology of architecture of green building determines the strategy of saving material, energy and water resources (in Fig. 3) [1]. Green building is, therefore, in the technology of the architecture qualitatively higher notion than energy-saving building, or low energy (solar) building. Low energy building is a contribution, a predecessor - a positive step towards green building (in Fig. 4). The same relation of quality is between low energy (solar) architecture and green architecture (in Fig. 4).

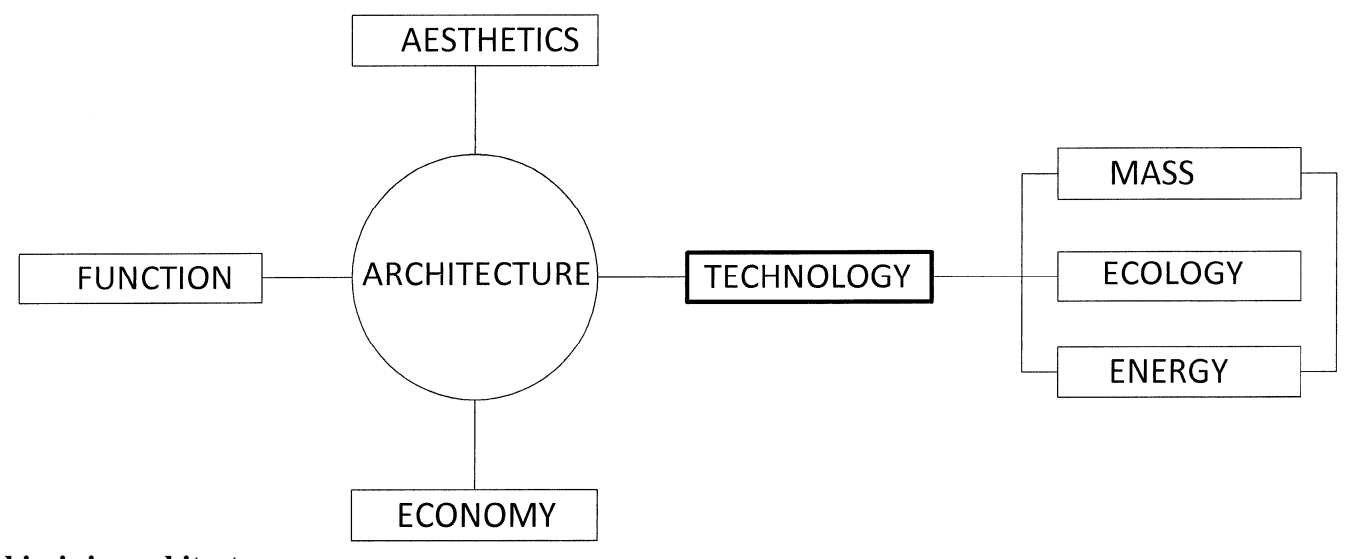

Fig. 1 Symbiosis in architecture.
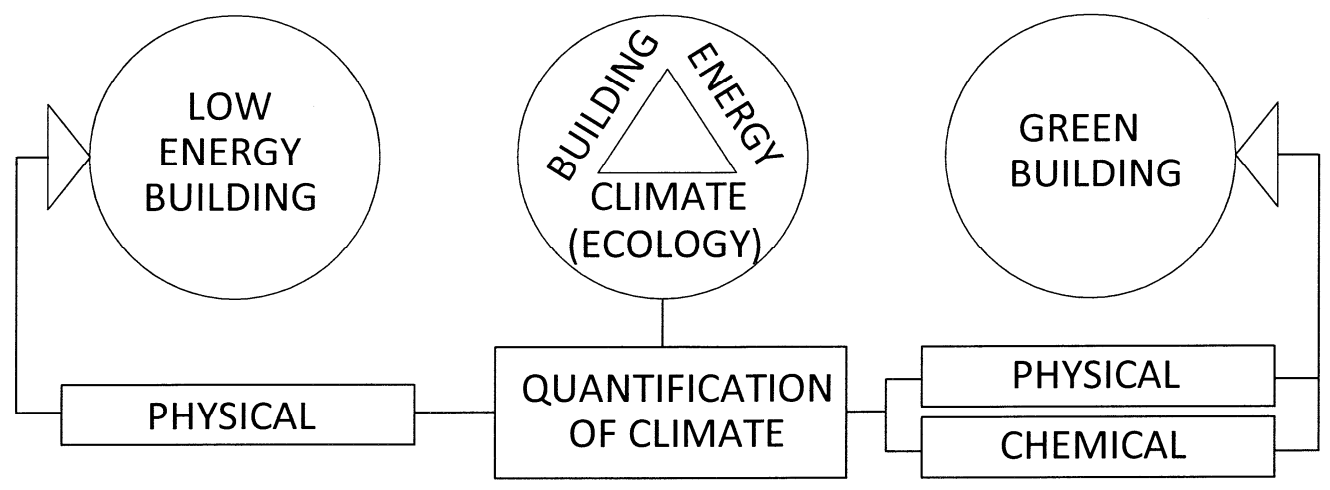

Fig. 2 System relation in the technology of architecture.
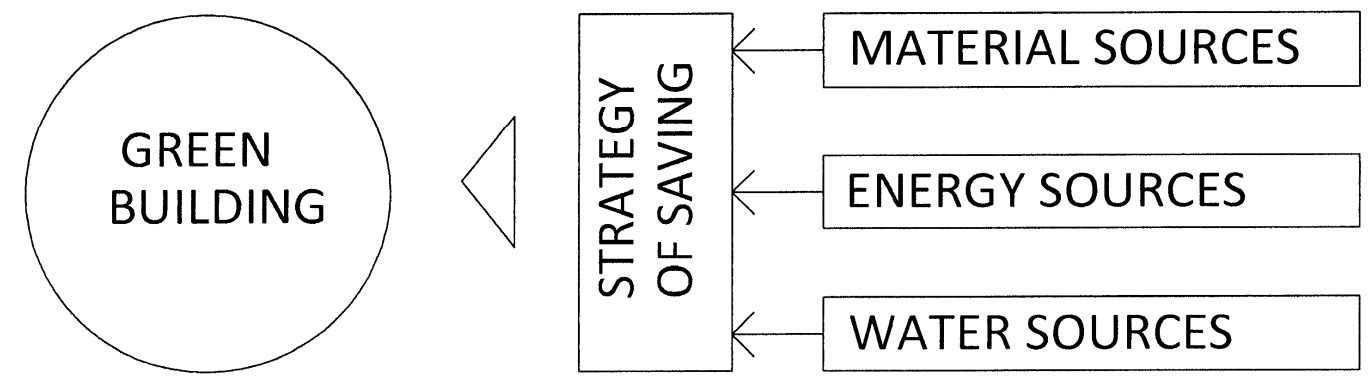

Fig. 3 Low energy (solar) architecture and green architecture. 


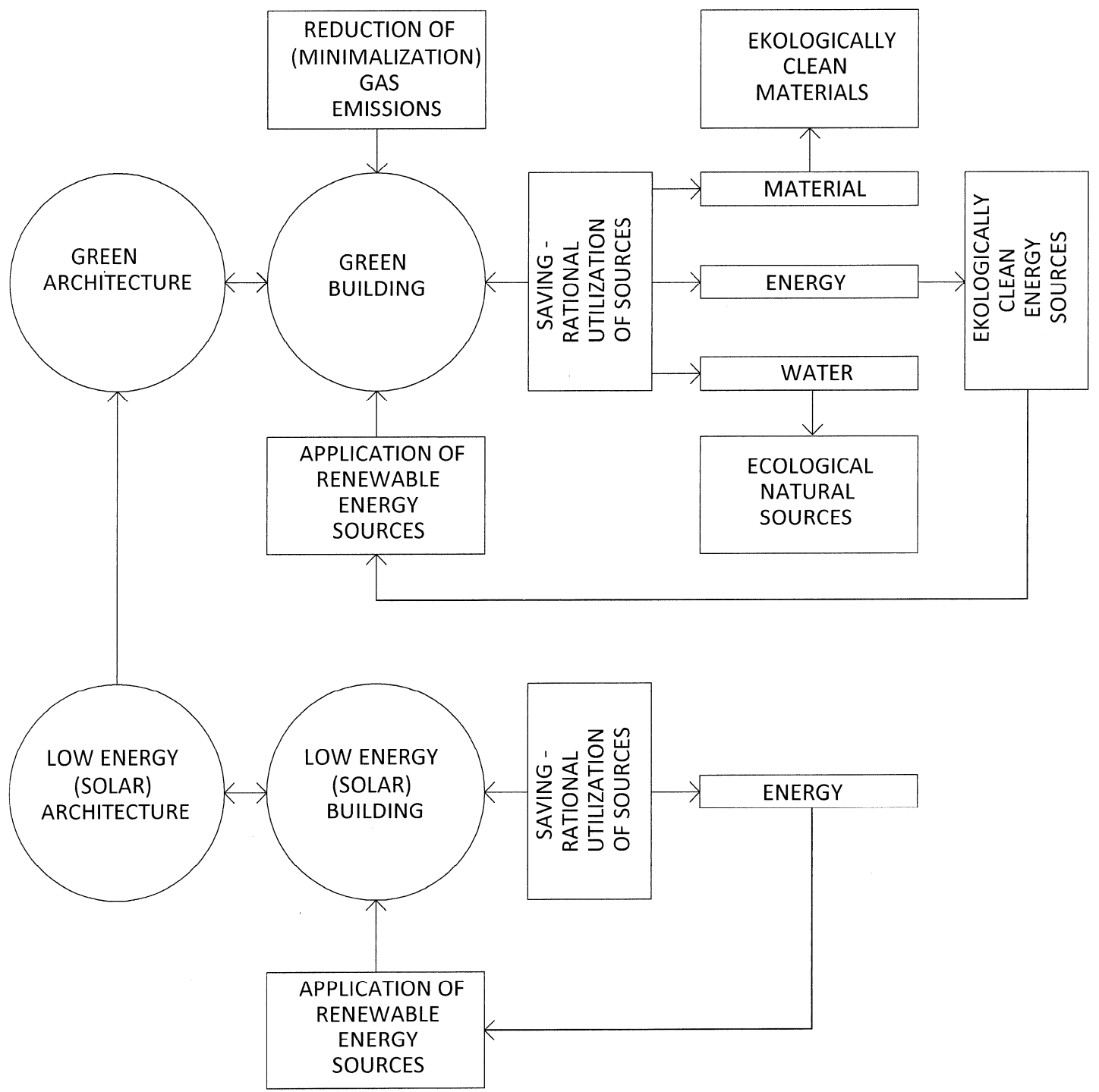

Fig. 4 Low energy (solar) architecture and green architecture.

\section{Green Architecture versus Sustainable Architecture}

With the new approach or significant specification of the term ecology in modern age of information is the notion sustainable development of the society. It is the synonym for the image of future world, the aim of which is to put man-nature-technology into consistent equilibrium. It means such a development which would for the contemporary and future generations:

- maintain their basic living needs;

- decrease the variety of nature;

- preserve the function of ecosystems.
Sustainability is therefore satisfaction of the needs of the contemporary generation, without breaching the ability of future generations to satisfy their needs. Sustainable architecture must also contribute to the sustainable development of the society. Sustainable and green architecture are often attributed with fallacious synonyms in various forms. Sustainability according to the above mentioned definition means not having a negative impact on the environment. Green building is therefore a contribution to sustainability, its predecessor - a positive step towards sustainable building. Sustainable building is in the technology of architecture qualitatively higher notion than green 
building. The same relation of quality is between sustainable architecture and green architecture.

\section{Green Building}

Which building can be attributed with the character-status of green building? The one which in the field of architectural technology [1, 2]:

- accepts strategic fields of systematic saving of material, energy and water resources (Fig. 4);

- utilizes renewable sources of energy (Fig. 4);

(Note: In the conceptual and schematic project, creation accepts minimally passive solar system.)

- utilizes ecologically clean - nontoxic building materials (Fig. 4);

- takes into account climatic changes; systematically reduces - minimizes gas emissions, particularly carbon dioxide emissions $\left(\mathrm{CO}_{2}\right)$, as a main product from the fuel system of building, as a crucial indicator of the ecology of exterior climate (Fig. 4);

- provides high standard of comfort in the creation of optimum artificial — architectural environment.

\section{Structure of Design Strategy for Green Building}

Structure of the strategy of green building comprises several significant fields fundamentally influencing schematic and graphic design in the complex process of its design creation [1] (Fig. 5). The subject structure includes those strategic elements which define and emphasize the principles and the concepts of green building [2, 3] (Fig. 6).

Green building in its basic strategy is defined as a building with systematic saving - rational utilization of material, energy and water resources A, B, C (Fig. 6).

In the field of materials green building is in its basic strategy defined by the orientation on the ecologically clean masses A (Fig. 6) and equally on the ecological manufacturing of building materials for material construction design of details, elements and systems of buildings A1 in Fig. 6.
According to the fact that the manufacturing of building materials is the primary field of material engineering and is connected with the design creation only in the field of application, the fact is also accepted in the inner design structure of the strategy for the principles and concepts of green building (Fig. 6).

In the field of energetics the green building is in its basic strategy defined by the orientation on ecologically clean sources B in Fig. 6 namely above all on self-renewable alternative energy sources and equally on the ecological manufacturing of energy B1 in Fig. 6 for the widest scale of energy demand and consumption connected with the creation of the optimal artificial - architectural environment of buildings. Therefore the interaction "renewable sources" and "ecological energy production" is a serious element of inner structure of the strategy, emphasizing the principles and concepts of green building.

In the field of water resources the green building is in its basic strategy defined by the orientation on ecologically clean natural sources C in Fig. 6 and equally on their systematic protection from pollution by waste $\mathrm{C} 1$ in Fig. 6. Therefore the interaction "water" and "waste" and the interaction "territory" and "vegetation" are serious elements of inner structure of the strategy, emphasizing the principles and concepts of green building (Fig. 6).

The listed three fields of basic structure of the strategy of green building lead into the effort to optimize the reduction of produced gas emissions and energy consumption in the building A, B, C in Fig. 6 and to the effort of the final program not to decrease the "variety of nature", preserve the "functions of ecosystems" and provide "living needs" for future generations A, B, C (in Fig. 6) which represents the program of sustainable building in the program of sustainable development of the whole society.

The inner structure of this basic strategy of green building represent strategic elements which emphasize the principles and the concepts of green building (Fig. 6). These include: 


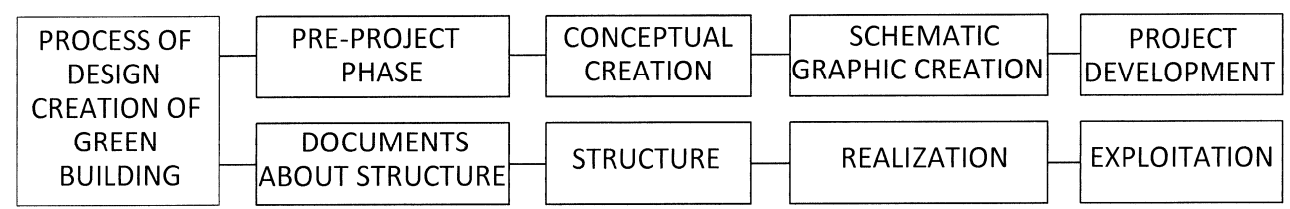

Fig. 5 Scheme of the process of green building design.

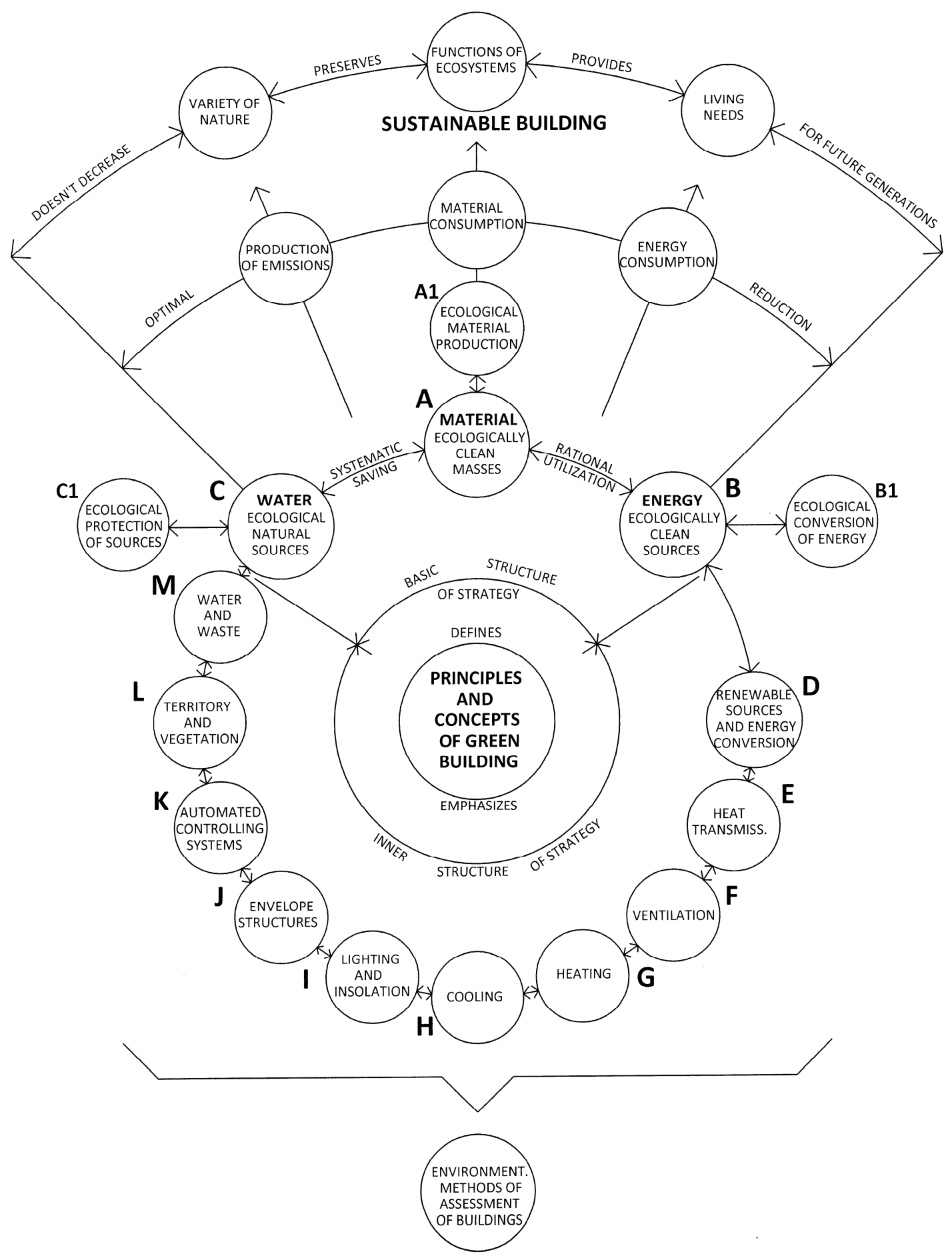

Fig. 6 Structure of the design strategy according to the principles and concepts of green building. 
- strategy of application of self-renewable alternative energy sources and connected ecological conversion of primary and secondary energy D in Fig. 6;

- strategy of heat transmission as a basic parameter for hygienic criterion of the envelope structures of buildings and one of the determining criteria of energy demand of building $\mathrm{E}$ in Fig. 6;

- strategy of ventilation of green building as one of the basic parameters of the quality of interior climate, expressed by its ecology and the rational utilization of energy $\mathrm{F}$ in Fig. 6;

- strategy of heating of green building [4] with the orientation on the application of alternative sources, rational utilization of energy and the reduction of emission production G in Fig. 6;

- strategy of cooling of green building [4] equally with the orientation on the application of alternative energy sources, the utilization of natural phenomena and the reduction of emission production $\mathrm{H}$ in Fig. 6;

- strategy of lighting and insolation of green building [4], providing the visual comfort in the creation of artificial architectural environment and co-operating in the creation of healthy building (insolation) I in Fig. 6;

- strategy of exterior envelope providing the rational utilization of ecologically clean materials from its ecologically clean production and co-operating in the rational utilization of energy and the ecological creation of architectural environment $\mathrm{J}$ in Fig. 6;

- strategy of automated systems of control which are today already indispensable tool of modern intelligent building of contemporary age of information $\mathrm{K}$ in Fig. 6;

- strategy of the interaction of territory and vegetation, providing the orography of territory and vegetation as a mutually conditioning ecological unit $\mathrm{L}$ in Fig. 6;

- strategy of interaction of water and waste, providing the ecological design and protection of water resources, the rational utilization and control of water managements, ecological processing or disposal of waste M in Fig. 6.

\section{Conclusions}

It is important to be aware of the fact that the capital of nature enters into the economy of man with its new economic values that result in finding new value relations of the organization, the economy and the transformation of society. Further development of the basic interaction society-energy-ecology would be impossible without the application of ecologically clean renewable energy sources and society-wide shift towards low energy, low-emission production technology in all three core technical areas of society, representing industry, transport and human settlements. Renewable energy sources are therefore strategic commodity without which it is impossible to carry out any further economic activity. The world science reacts to this fact in architectural technology, namely in the field of human settlements, by new trends that are based on the development of the general interaction society-energy-ecology. It develops them equally, within the new conception of system relation building-climate-energy, in three levels that are defined by the terms low energy architecture, green architecture and sustainable architecture. In this development, the actual problem is represented by green architecture, being an important contribution - a positive step towards the target program of sustainable building. The character of green building in the context of green eco-architecture has to become a challenge for architects, not only for their active contribution to the shaping - the form and the aesthetics of green buildings, but also for mastering the complex of ecological, energy, material and water strategy of their design. The best way to utilize the strategy of green building is to theoretically understand the ecological, physical, chemical and construction - technological problems of modern technology in architecture. 


\section{Acknowledgments}

This work was supported by the Slovak Research and Development Agency under the Contract No. APVV-0624-10.

\section{References}

[1] A. G. Kwok and W. T. Grondzik, The Green Studio Handbook: Environmental Strategies for Schematic Design, Elsevier Inc., Oxford, 2007.
[2] P. Jodidio, Green Architecture Now!, Taschen GmbH, Cologne, 2009

[3] M. de Campagne and L. Häuser, Natural Flair, Evergreen GmbH, Köln, 2008.

[4] N. Lechner, Heating, Cooling, Lighting: Sustainable Design Methods for Architects, John Wiley \& Sons, Inc., New Jersey, 2009. 